\title{
SAUDEMENTAL.PT - 3 YEARS OF EHEALTH LITERACY
}

II M. Silva', R. Laia', B. Lourenço', B. Ferreira², M. Gonçalves', A. Nobre'

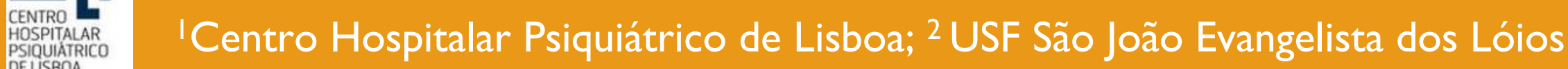

Objectives: To present saudemental.pt and review its activity over the course of 3 years.

Background and aims: Saudemental.pt is an informative web platform for the general population about mental health. It was developed in 2015 through a partnership between Centro Hospitalar Psiquiátrico de Lisboa and the community primary health care.

Designed as a simple, intelligible and accessible platform its mission is to provide clear and reliable information about mental health, helping in the recognition, management and prevention of mental disorders, along with fighting stigma and promoting healthy lifestyles.

Inspired by the growing role of electronic health information as a mean to influence individuals in managing their health and interact with the health care system, the portal intends to empower individuals to make informed decisions and actively engage in their own mental health care.

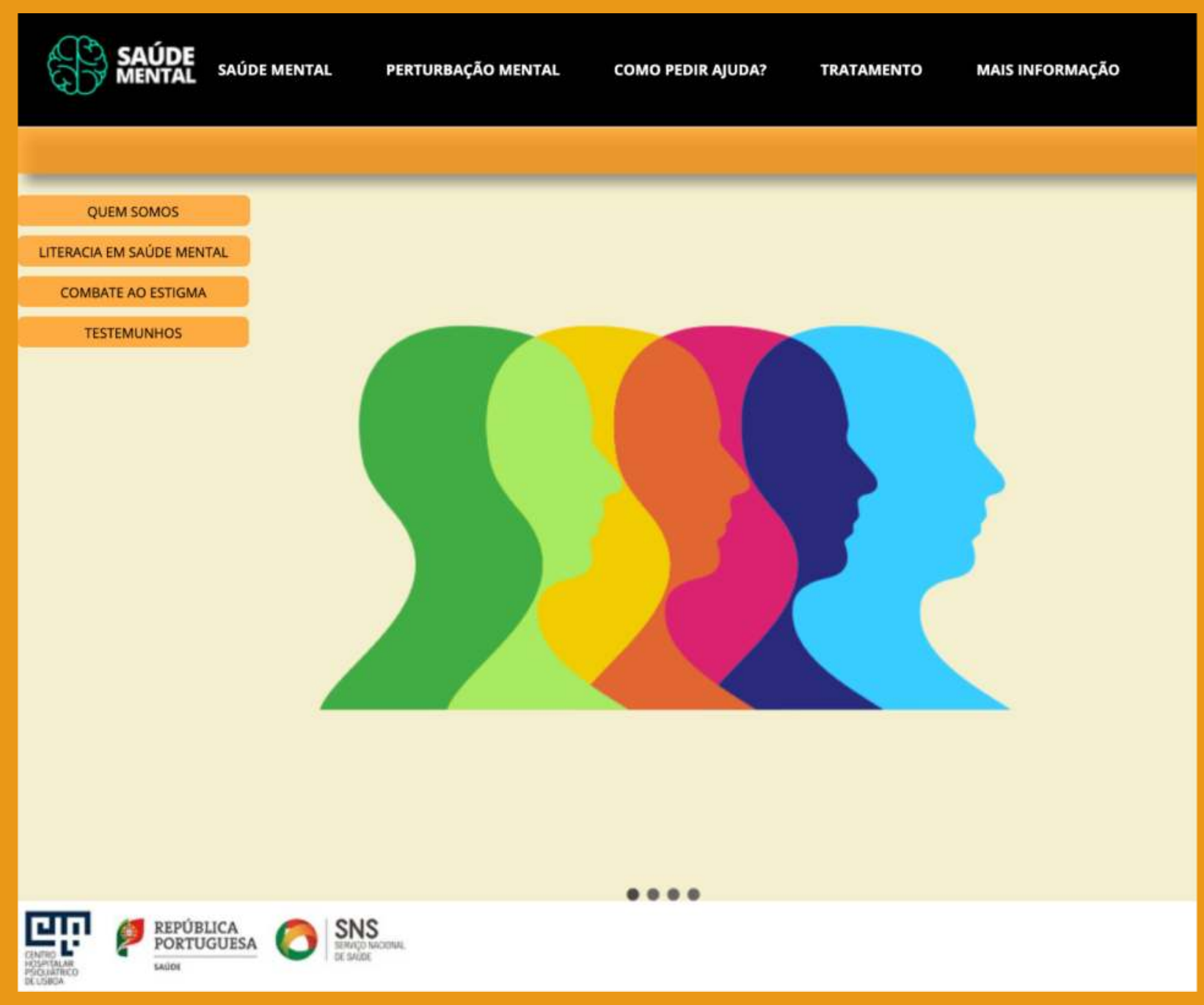

Materials and methods: Descriptive statistical analysis (google analytics) of saudemental.pt users from january/2016 until december/2018. Review of selected literature.

Results: The portal was visited by $\mathbf{8 8 . 5 2 7}$ users during the 3 years. There was a substantial increase in the number of visitors, from 9.172 in 2016 to 59.292 in 2018 . New users were accountable for $84 \%$ of visits. The majority were estimated to be male (54\%) and under 35 years old (6I\%).

Number of users (per year)

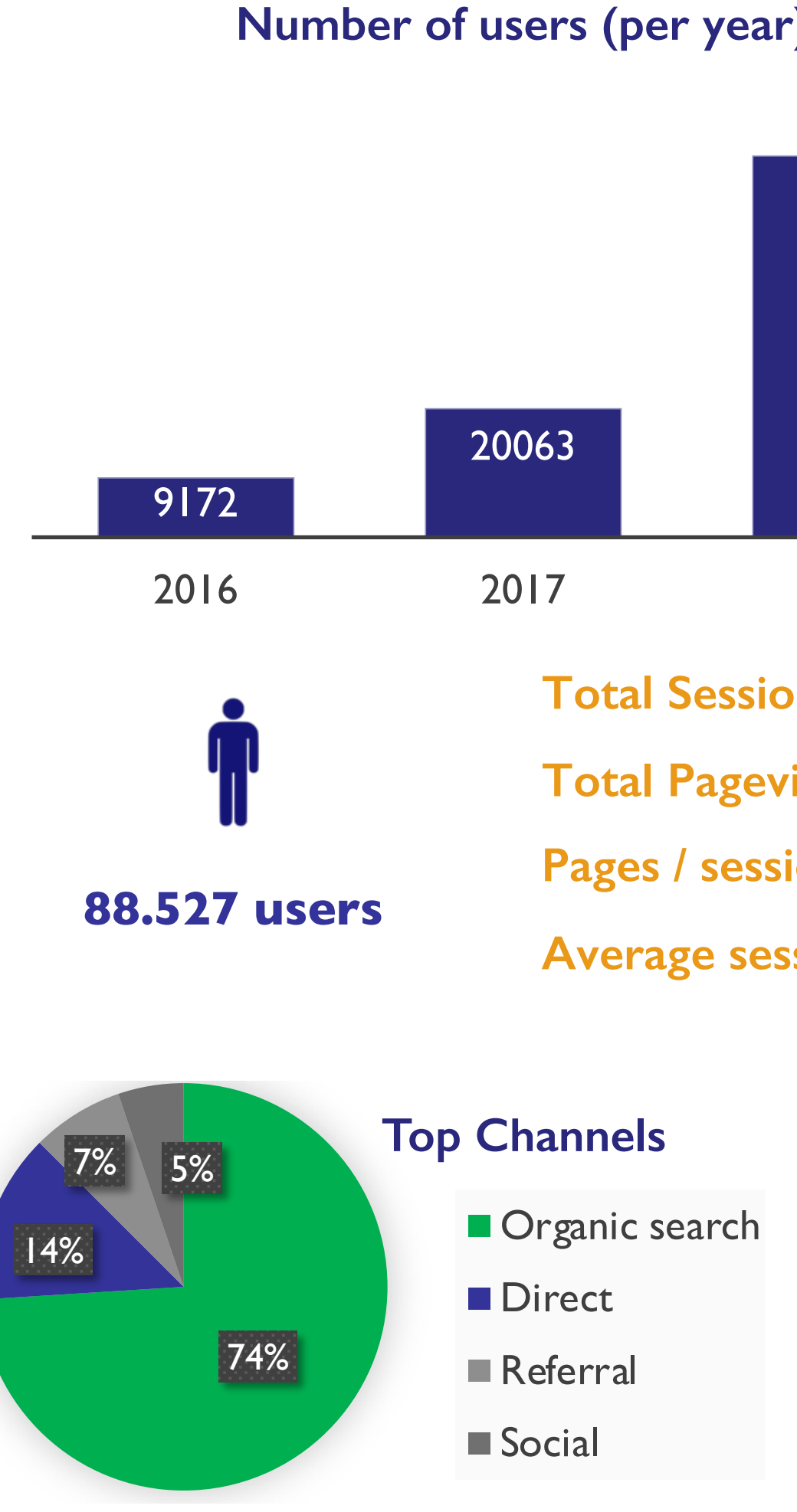

Users

Gender

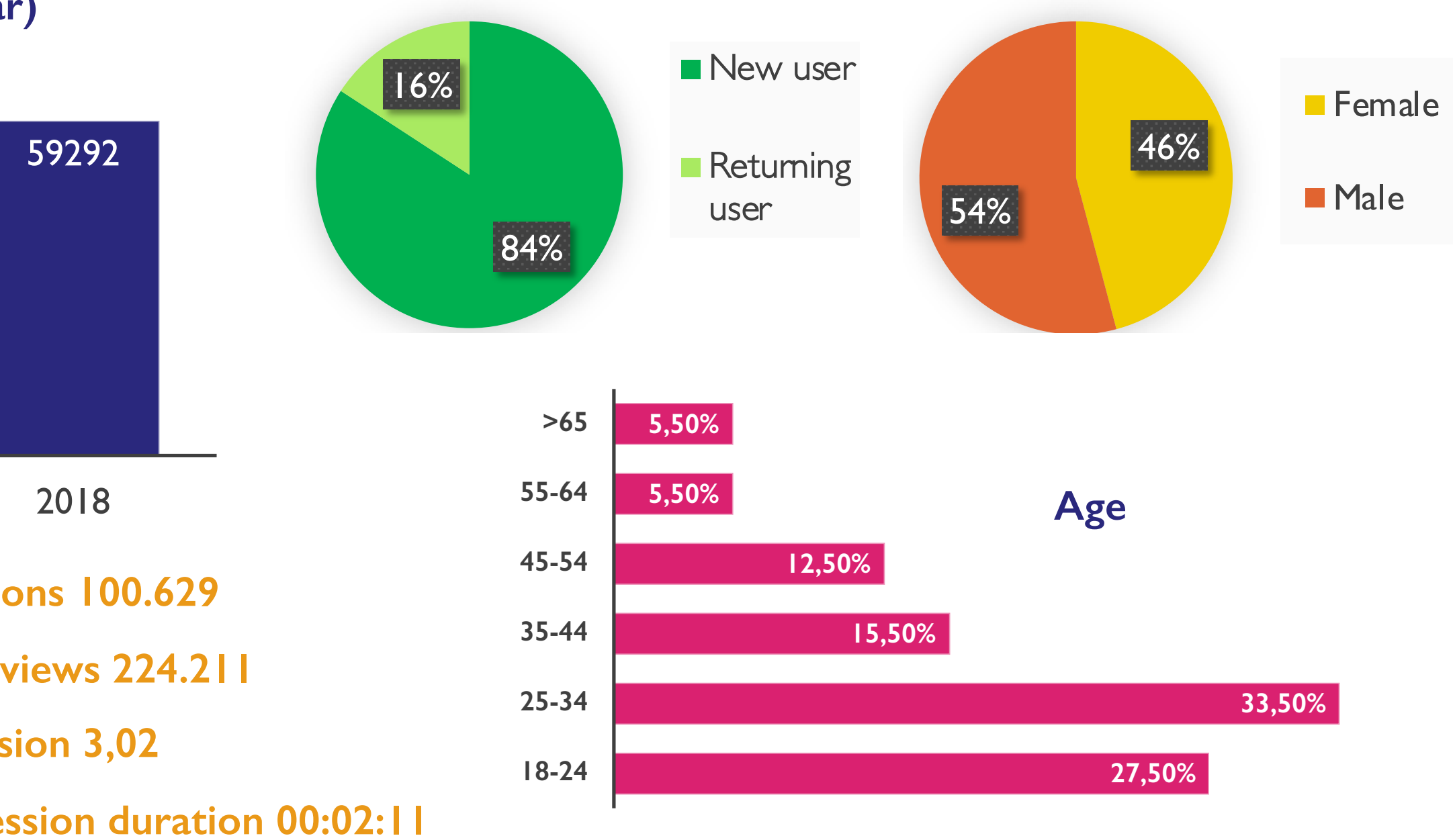

On average, each user visited 3,02 pages per session, with mean duration of 2 minutes per visit. Entries came mainly from Portugal (74\%), followed by Brazil (14\%), Mozambique (2,4\%) and Angola (1,99\%). Organic traffic through search engine - was responsible for the majority of entries (74\%), followed by direct traffic - through browser - (13,5\%). The most visited content was "Schizophrenia", accountable for $24 \%$ of pageviews, followed by “Mental Disorder" (I 5, I7\%) and "Bipolar Disorder" (6,63\%). 